\title{
As motivações de professores de ciências para a formação contínua a distância
}

Science teachers' motivation for distance education

\author{
Paulo Sérgio Garcia \\ Nelio Bizzo \\ Universidade de São Paulo
}

\section{Resumo}

Este estudo tem por objetivo evidenciar e analisar o perfil e as motivações de professores de ciências que participaram de programas de Formação Contínua a Distância (FCD). Analisou-se a motivação inicial (MI), os motivos que atraem esses professores para FCD, relacionando o perfil desse professor (gênero, idade) a essa motivação inicial. Analisaram-se também os fatores que mantiveram esses profissionais motivados durante a formação. Os dados foram coletados ( $N=75)$ através de entrevistas e questionários. As análises permitiram categorizar os fatores da MI em três domínios: pessoal, profissional e de conveniência. Apesar de certo equilíbrio, o domínio profissional foi mais determinante para atrair os participantes. $\bigcirc$ tema, a relevância dos conhecimentos e a flexibilidade de horários foram decisivos para manter o interesse dos professores durante a formação. Com esses resultados, universidades e formadores dispõem de elementos para atrair e manter os professores em programas de FCD, contribuindo, dessa forma, para a melhoria do Ensino de Ciências.

Palavras-chave: Motivação. Formação contínua a distância. Professores de ciências.

\section{Abstract}

IThis study aims to highlight and analyze the profile and motivations of science teachers who participated in distance continuing education programs (DCE). On one hand, we analyzed the initial motivation (IM), the reasons that attract these teachers to DCE, associating the features of the teacher (e.g. gender, age, education, technology) to that initial motivation. On the other, we analyzed the factors that held these professionals motivated during the DCE. Data were collected ( $N=75)$ through interviews and questionnaires. The analysis, qualitative and quantitative, allowed categorizing the $I M$ in three domains: personal, professional and convenience. Although there is certain balance the professional domain was more crucial to attract participants. Teachers with graduate degrees and greater experience in teaching were also more influenced by the professional domain. Concerning to the motivation during the DCE, the theme, the relevance of the knowledge and flexible schedules were important factors to keep teachers' interest. Based on these results, universities have important elements to attract science teachers to DCE and to maintain their interests, thus contributing to the improvement of science education.

Keywords: Motivation. Distance Continuing education. Science teachers. 


\section{Introdução}

professor desempenha um papel crucial para a qualidade do Ensino de Ciências (CUNHA; KRASILCHIK, 2000), para a implementação de reformas (ADAMS; TILLOTSON, 1995) e para melhorar o desempenho dos estudantes nos testes nacionais e internacionais.

Neste sentido, a expansão de programas de formação contínua para esses profissionais é crucial, e as universidades públicas podem ampliar ainda mais seus papéis frente à Educação e à sociedade, utilizando, para tal, a Educação a Distância (EaD) através de abordagens inovadoras para a formação de professores.

Para criar programas atraentes de Formação Contínua a Distância (FCD) para professores de ciências, é necessária, entre outras coisas, uma compreensão profunda sobre as características desses profissionais, sobre os motivos que os atraem para esse tipo de formação e o que os mantém motivados ao longo da aprendizagem.

A literatura tem procurado compreender as características (o perfil) e a motivação inicial (as razões que atraem esses estudantes para a EaD) dos alunos bem-sucedidos que estudam a distância IGIBSON, 2003; RURATO; GOLVEIA; GOLVEIA, 2007), com o objetivo de construir estratégias para facilitar o processo de aprendizagem. No entanto, Palloff e Pratt (2003) questionam se esse é o perfil realmente do aluno de sucesso, acreditando que, mesmo estudantes que não correspondam completamente às características ideais de um aluno virtual, possam também ser bem-sucedidos. Segundo as autoras, é necessário para esses estudantes maior estrutura no ambiente on-line.

Rurato, Golveia e Golveia (2007a) propuseram uma abordagem transversal para compreender as características e motivações dos estudantes de EaD, já que esses dados fornecem elementos para a construção de estratégias de aprendizagem. Outros estudos também têm explorado o perfil e os motivos que levam os adultos a procurar FCD. Fiuza (2002) mostrou que os alunos eram atraídos para cursos de EaD, com leve predominância, pelos fatores pessoais. Nosso grupo demonstrou (GARCIA; BIZZO; LEMOS, 2008) que motivos profissionais foram importantes para atrair professores de ciências para a FCD. 
A maioria dessas pesquisas, no entanto, não separa os motivos entre os subgrupos dentro da mesma população, relacionado ao perfil do professor. Elas ficam circunscritas à investigação e à análise do perfil e da motivação inicial, de forma isolada, somente elencando alguns fatores e não avançam para a compreensão de outras variáveis também importantes como a motivação ao longo da formação.

A motivação do aluno ao longo da formação é uma variável essencial tanto para a potencialização da aprendizagem como para contribuir com a diminuição da evasão nos cursos a distância. (FERREIRA, 1985). Dados do Censo EaD Brasil do ano de 2010 mostraram que o nível educacional de maior evasão está associado aos cursos de extensão, aqueles de menor duração. A evasão em instituições que só oferecem esse tipo de curso chega a 29\%. (ABED, 2010).

Este estudo tem por objetivo evidenciar e analisar o perfil e as motivações de professores de ciências que participaram de programas de formação contínua a distância. Foram analisados os motivos que atraem esses professores para FCD, relacionando o perfil desse professor em termos de gênero, idade, formação, experiência no ensino, fluência tecnologia (relação com o computador, com a internet e com a EaDl a essa motivação inicial. Paralelamente, foram investigados os fatores que mantiveram esses profissionais motivados durante a FCD.

\section{Educação a Distância e formação contínua de professores}

A EaD, por meio de abordagens inovadoras, pode oferecer as condições necessárias para a expansão dos programas de formação contínua, atualizando, criticamente, os professores de ciências.

Decreto $n^{\circ}$ 5.622, de 19 de dezembro de 2005, publicado no Diário Oficial da União (D.O.U), revogou os dois anteriores (n².494, de 10 de fevereiro de 1998 e $n^{\circ} 2.561$, de 27 de abril de 1998), regulamentou o artigo 80 da LDBEN/ 1996 e estabeleceu a EaD em seu artigo $1^{\circ}$

[...] como modalidade educacional na qual a mediação didático-pedagógica nos processos de ensino e aprendizagem ocorre com a utilização de meios e tecnologias de informação e comunicação, com estudantes e professores desenvolvendo atividades 
educativas em lugares ou tempos diversos. (Lei de Diretrizes e Bases da Educação Nacional, 1996, p. 28).

Esse decreto instituiu também a obrigatoriedade de encontros presenciais para avaliações, estágios obrigatórios, defesa de trabalhos de conclusão de curso e atividades relacionadas a laboratórios.

Ministério da Educação (MEC) já promoveu várias políticas para a expansão da EaD. Merecem destaque a criação da Secretaria de Educação a Distância (Seed), o Programa de Apoio à Pesquisa em Educação a Distância (Paped), Prolnfo (Portaria, MEC/522), o Proformação e o Pró-Licenciatura, programas de capacitação de docentes. Como política mais eficaz, o MEC fez - lançamento do programa Sistema de Universidade Aberta do Brasil (UAB), pelo Decreto $n^{\circ}$ 5.800, de 8 de junho de 2006. A UAB vem promovendo cursos de formação inicial e contínua em várias regiões do país.

A expansão da EaD, segundo dados do Censo EaD Brasil do ano de 2010 , é grande. Os cursos de especialização a distância totalizaram 37\%, o maior grupo, do total de cursos (1.752) a distância acontecendo no país. (ABED, 2010). A maior parte desses cursos está endereçada à formação de 168 professores $(31,5 \%)$, devido ao déficit que é de aproximadamente 235 mil professores para o Ensino Médio em todas as áreas, 23,5 mil somente na disciplina de Física. (CUNHA, 2006).

Os programas de FCD estão se expandindo. Tal fato implica a criação de estudos que possam auxiliar as universidades públicas nessa ampliação com o objetivo de oferecer formação contínua de qualidade para os professores de ciências.

\section{O perfil e a motivação dos professores}

Palloff e Pratt (2003) sugerem que o perfil do aluno virtual de sucesso é, geralmente, caracterizado por pessoas com mais idade e maturidade, autodidatas que sabem conduzir sua agenda de estudo sem necessitar de cobrança do professor, motivados, sabem questionar, trocar informações e elaborar ideias.

A EaD tem sido uma escolha de vários grupos (tipos de perfis), que não podem frequentar a escola presencialmente. Ferreira e Mendonça (2007) 
afirmam que as mulheres consideram a EaD com uma boa alternativa de formação por questões do trabalho diário e dos afazeres de casa.

Em relação ao perfil do aluno que estuda a distância, Rurato, Golveia e Golveia (2007) afirmam que esse não é homogêneo, mas representado por características sociais, demográficas e situacionais. Gibson (2003) e Keegan (1996), ao analisarem dados estatísticos dos alunos de sucesso na EaD, mostraram que esses são organizados, persistentes, concentrados, automotivados, autodisciplinados, autônomos e se adaptam facilmente às mudanças. Os estudos sobre o perfil do aluno que busca a EaD em geral e a FCD em particular, suas características, fornecem elementos para dinamizar o trabalho pedagógico dos tutores nas atividades a distância.

No entanto, esse perfil em termos de sexo, idade, formação, fluência tecnológica, do aluno que estuda a distância não pode ser analisado isoladamente e deve ser relacionado com outras características como a motivação inicial e aquela ao longo da formação, pois tal situação fornece mais informações e de forma mais detalhada para aqueles que atuam na EaD.

A motivação é um processo interior no indivíduo que deflagra, mantém e dirige o comportamento. Ela é um estado psicofisiológico, um estado de tensão energética, resultante da atuação de fortes motivos que a impelem a agir, com certo grau de intensidade e empenho. (CAMPOS, 1993). $\bigcirc$ tema tem suscitado investigações de pesquisadores de diferentes áreas do conhecimento. Caracterizando-se como um componente interno do sujeito, a motivação é fundamental para o entendimento das atitudes, dos comportamentos, das aprendizagens, do desempenho, da participação em FCD.

Por não ser um fenômeno diretamente observável, a motivação é investigada através do estudo do comportamento das pessoas, com o intuito de identificar e compreender os motivos subjacentes às suas inclinações e ações. Murray (1986) afirma que, apesar de existirem múltiplas visões e concepções sobre a motivação, há um consenso de que é o motivo, como fator interno, que inicia, conduz, mantém e integra o comportamento da pessoa.

Os motivos, segundo Hersey e Blanchard (1986), são sinônimos de desejos, instintos, impulsos, necessidades, interesses da pessoa orientados para objetivos conscientes ou inconscientes, e a motivação está relacionada com a intensidade desses motivos. Os indivíduos apresentam muitos motivos 
que concorrem entre si e os mais intensos, de maior intensidade, são os que levarão a pessoa a agir.

Para Lima (2000), um motivo é um constructo que não pode ser observado, e é construído pelo sujeito para explicar por que ele tem a necessidade de agir desta ou daquela forma para a realização de uma ação. Desta forma, tanto a força de cada motivo como o padrão deles têm impacto no modo como a pessoa compreende e interage com o mundo que a rodeia.

Bergamini (1992, p. 109), procurando mostrar que o comportamento, a motivação associa-se com os objetivos da pessoa, afirma que "[...] toda a força do comportamento está sempre dirigida para um alvo. As pessoas buscam saúde, conforto, bem-estar e fogem das condições que ameaçam a saúde, o conforto e o bem-estar."

Os adultos apresentam vários motivos (motivação) para aprender e para fazer escolhas quanto à aprendizagem. Em relação aos motivos que levam os adultos aos cursos a distância, nos Estados Unidos, Moore e Kearsley (2007) colocam que os alunos apresentam como motivos iniciais para se matricularem em cursos de EaD a realização de créditos universitários, a busca por novos conhecimentos, o investimento pessoal, a tentativa de melhorar a renda e a empregabilidade.

Fiuza (2002) elencou um conjunto de fatores motivadores que levam os profissionais a procurar a EaD. A autora agrupou a frequência das respostas dos alunos mostrando ligeira predominância dos aspectos pessoais sobre os de ordem profissional. Em outro estudo Gomez (2000) mostrou que os participantes tinham como motivação inicial para buscar o curso fatores profissionais, pessoais e práticos.

O'Lawrence (2007) revelou que os adultos participam de programas de EaD para aprimorar suas habilidades, pela pressão de ter de conquistar um diploma, por causa de incentivos que eles recebem de seus empregadores, por falta de tempo, pelas questões complicadas de transporte, para manter equilíbrio entre o trabalho e família e pela flexibilidade da formação.

$\bigcirc$ autor aponta ainda outros fatores que influenciam os aprendizes adultos a participar de programas de EaD. Os adultos possuem uma variedade de experiências de aprendizagem e trabalho; podem integrar novos conceitos ao conhecimento prévio compreendendo as ideias de seus colegas com experiência em trabalhos similares; eles desejam desfrutar de aplicações práticas; 
aprendem melhor por ter controle sobre seu ambiente de aprendizagem e ter a oportunidade de mostrar seus talentos ao grupo ou em projetos especiais; gostam de participar voluntariamente de experiências de aprendizagem, e a maioria deles pensa que sabe mais do que seus instrutores e, infelizmente, a maioria dos professores não contesta esses indivíduos. (O'LAWRENCE, 2007).

A motivação é um dos elementos fundamentais para a aprendizagem. Ferreira ( 1985) afirma que ela é essencial no ensino a distância para o sucesso do aluno. $O$ tema, além de ser alvo de pesquisas relacionadas com a motivação inicial, também vem sendo analisada em relação à aprendizagem ao longo da formação, considerando sua importância para a potencialização da aprendizagem e para a diminuição da evasão dos alunos nos cursos.

tema evasão relaciona-se à desistência em definitivo do aluno de um curso em qualquer de suas fases, incluindo, como afirma Favero (2006), os alunos que se matricularam e nunca se apresentaram. A evasão, então, engloba a desistência dos estudantes desde a matrícula até o final do curso.

Existem muitas causas em relação à evasão na EaD. Coelho (2010) cita, entre outras, a falta de domínio técnico do uso do computador e da internet, falta de encontros presenciais, e dificuldade na exposição de ideias na comunicação escrita. Xenos, Pierrakeas e Pintelas (2002) consideram que a evasão é um dos principais problemas das instituições de ensino a distância. Os autores classificam esses fatores em endógenos, relacionados a certas características demográficas dos estudantes, como idade, sexo, estado civil, número de filhos, tipo de trabalho ou profissão; e exógenos, ligados, por exemplo, aos cursos, aos tutores, ao material.

Entre outros fatores internos citados por esses autores, que explicam o fenômeno da evasão, estão também a percepção de dificuldade em relação ao curso, a motivação do aluno, a persistência e a carga de trabalho. Em relação aos fatores externos, o desempenho do tutor, como citado, está relacionado com a qualidade e quantidade de apoio oferecido ao estudante e as interações com os alunos.

Para Santos, Tomotake, Oliveira Neto, Cazarini, Araújo e Oliveira (2008) algumas propostas e estratégias podem combater a evasão. Por exemplo, capacitação do tutor, oferecimento de cursos para maior familiarização com a EaD, atividades que estimulem e motivem o estudante no início e durante a formação, apresentação de um manual do aluno contendo os requisitos 
necessários para a EaD, a fim de evitar frustrações quanto às expectativas iniciais. Para Favero e Franco (2006, p 155), o diálogo se constitui numa boa ferramenta para motivar os alunos, pois, quando os estudantes se sentem parte do processo eles "[...] se motivam e continuam, não evadindo." Os autores argumentam que as interações realizadas no ambiente virtual de aprendizagem através de ferramentas próprias possibilitam o diálogo ao longo do curso. Para tal, os alunos devem ser instigados a participar e colaborar com os colegas. Desta forma, os estudantes se sentem parte de um grupo.

\section{O curso de formação contínua de professores de ciência a distância}

Trata-se de um curso gratuito, sem cobrança de nenhum tipo de taxa, sem patrocínio de nenhum fabricante de produto alimentício industrializado ou in natura, oferecido para professores que ministrem a disciplina Ciências no Ensino Fundamental e que estejam em efetivo exercício em sala de aula, em escolas da Educação Básica, e estudantes de cursos de licenciatura.

172 objetivo da formação, de acordo com o Programa Oficial do Curso, é o de atualizar professores de ciências (PC) na temática nutricional, a partir de elementos familiares aos alunos do Ensino Fundamental, explorando a, então, recente legislação sobre rotulagem de alimentos. São abordadas as atuais modificações das normas da Agência de Vigilância Sanitária (Anvisa) que disciplina a rotulagem de alimentos, bem como recomendações de consumo de alimentos, a fim de proporcionar ao professor da disciplina Ciências elementos teórico-práticos suficientes para lidar com a tradicional prática de estudar rótulos de alimentos industrializados em sala de aula. (FEUSP, 2007).

$\bigcirc$ curso teve a duração de nove semanas, disponibilizou 120 vagas, com 60 horas, sendo 58 a distância e duas para as provas finais presenciais, atendendo às especificações das normas da Universidade de São Paulo (2003), Resolução CoCEx, de 25 de março de 2003, que regulamenta a EaD na USP.

curso utilizou oito (8) videoaulas juntamente com slides Power-Point, referentes a cada aula, para serem utilizados ao longo da formação. Há também no final do curso uma videoaula de revisão. 
As videoaulas ficaram armazenadas em sítio da Faculdade de Educação da Universidade de São Paulo. Elas eram disponibilizadas semanalmente, contando com um grande número de acessos realizados. A aula 8, por exemplo, que discutiu assuntos como os tipos de fibras alimentares, as relações entre elas e o câncer, contou com mais de 230 acessos na semana de sua veiculação na primeira versão do curso.

Os conteúdos da formação a distância, inseridos no Programa Oficial do Curso, relacionavam-se às perguntas frequentes dirigidas a professores de ciências sobre rótulos de alimentos. Por exemplo, a legislação brasileira sobre rotulagem de alimentos; a Anvisa e suas Resoluções da Diretoria Colegiada (RDC); a microbiologia alimentar e a conservação de alimentos; as gorduras monoinsaturadas e polinsaturadas, os lipídeos interesterificados, etc. (FEUSP, 2007).

Os conteúdos apresentados nas aulas foram contextualizados através de problemas, perguntas e desafios, que tinham o objetivo de incentivar os PC na busca de soluções. Todas as aulas iniciavam com uma pergunta a fim de introduzir o PC ao tema, que era respondida ao final da mesma aula.

A cada semana uma videoaula é disponibilizada aos PC, juntamente com o material de apoio para ser impresso. Todas as videoaulas terminavam com perguntas do tipo "atividade de casa", que eram corrigidas no início da aula seguinte. Isto tinha o intuito de criar nos PC novas expectativas quanto ao novo conteúdo a ser tratado e manter a participação nos desafios propostos. As aulas também traziam pesquisas recentes veiculadas em jornais e internet, em particular em sites especializados e eram apresentadas relacionadas com a realidade conhecida ou vivida pelos PC.

Os PC podiam assistir às aulas durante a semana, enviar comentários, fazer perguntas, contribuir com o envio de materiais tais como textos e tabelas. Isso, de fato, ocorria, como foi observado nas análises dos emails trocados ao longo da formação.

As orientações para os PC aconteciam via videoaula e, sobretudo, por correio eletrônico. Essas orientações tinham sentido formativo (informações sobre a manutenção da motivação do aluno, importante em cursos a distância) e informativo (cronograma do curso). Outras orientações formativas aconselhavam os PC sobre o estudo a distância e suas demandas. 
Entre as metodologias utilizadas no curso foram planejadas formas de interação com sessões "tira-dúvidas" e discussões em horários previamente agendados. A metodologia enfatizava a interação e a aprendizagem colaborativa entre o professor coordenador e os professores. Essa modalidade de interação tinha a deliberada intenção de manter sincronia na turma de alunos.

A interatividade dos alunos com a equipe de apoio foi inicialmente planejada em diferentes formas de atendimento aos estudantes. Ela pretendia ser diacrônica, a partir de interações via email ou por acesso remoto à internet; sincrônica, a partir de contato telefônico em horários previamente divulgados e pelo computador em horários preestabelecidos.

A principal estratégia para manter sincronia das turmas do curso denominava-se "pergunta relâmpago". A pergunta tinha caráter, eminentemente, participativo (motivação extrínseca) e era caracterizada como uma atividade com horário programado, geralmente no fim de semana. Ela constava de um desafio, ou um problema, e visava levar os PC à reflexão sobre os assuntos discutidos nas aulas. Ao ser transmitida trazia um horário-limite para a resposta, a fim de contabilizar na participação do aluno. Essa atividade, que acontecia toda semana, tinha o objetivo de manter os PC em ritmo constante ao longo 174 das oito semanas, interagindo com o professor coordenador e com os demais colegas.

No final das aulas, da semana, as dúvidas, comentários, discussões em relação às perguntas relâmpago, ou novas informações eram enviadas para todos os professores com o objetivo de manter o grupo participando de tudo o que acontecia no curso.

O processo de avaliação do curso era composto de três instrumentos: a prova final presencial, que aconteceu na própria Universidade de São Paulo, o trabalho escrito e a participação nas atividades semanais. A prova final presencial, com três modelos $\mathrm{A}, \mathrm{B}$ e $\mathrm{C}$, tinha o valor de 5, 0 pontos, e buscava avaliar a aprendizagem sobre o conteúdo conceitual trabalhado ao longo do curso. Ela era composta de 36 questões de múltipla escolha, tinha caráter individual, sem consulta e com duração de duas horas.

$\bigcirc$ trabalho escrito, com valor de até 4,0 pontos, tinha de ser realizado em grupo e sua apresentação podia seguir uma das três opções: resenha, descrição de atuação em sala de aula, ou análise crítica da composição de alimentos. 
Outro critério de avaliação foi a participação no curso, tomando-se como base a qualidade e a pertinência desta em forma de perguntas e questionamentos, afirmações e sugestões. A estratégia da "pergunta-relâmpago" - que era sempre um problema sobre um assunto da aula da semana - caracterizava-se como uma das formas de participação avaliada durante o curso.

\section{Metodologia}

Este estudo tem por objetivo evidenciar e analisar o perfil e as motivações de professores de ciências que participaram de programas de formação contínua a distância no contexło da universidade pública. Foram analisados os motivos (motivação inicial) que atraem esses professores para FCD, relacionando o perfil desse professor em termos de gênero, idade, formação, experiência no ensino, fluência tecnologia (relação com o computador, com a internet e com a EaD) a essa motivação inicial. Investigamos, paralelamente, os fatores que mantiveram esses profissionais motivados durante a FCD.

A metodologia de estudo de caso foi utilizada, iá que ela é adequada para descrever um fenômeno, um evento ou uma situação no seu contexto, criar hipóteses, testar teorias. (YIN, 2005). Objetiva-se com o uso dessa metodologia descrever uma situação em profundidade, coletando dados por meio da utilização de múltiplas fontes, integrando e encadeando as evidências. $\bigcirc$ estudo de caso adotado é do tipo descritivo e exploratório. (YIN, 1993).

Os professores participantes deste estudo foram selecionados, considerando suas participações de cursos de FCD no ano 2007 promovidos pela Feusp. O curso foi selecionado por ser gratuito, de formação contínua, para professores de ciências no efetivo exercício da profissão e realizado em uma universidade pública.

Para coletar os dados, foram utilizados a técnica de entrevista e um questionário, contendo questões objetivas e uma escala de Likert. Essa coleta de dados mista possibilitou a triangulação de métodos, favorecendo a validade dos dados. (FLICK, 2009).

A técnica da entrevista foi utilizada com 12 professores de ciências que realizaram o curso no primeiro semestre de 2007, das cidades de São Paulo, Mogi das Cruzes e de São Caetano do Sul. Esses professores foram selecionados considerando que eles estavam ministrando a disciplina Ciências 
no ensino fundamental II, residiam em cidades diferentes e eram tanto professores aprovados (09) como reprovados (03) no curso.

A entrevista, semiestruturada, coletou informações sobre o perfil e sobre a motivação inicial ao longo do curso. No perfil, foram selecionadas informações pessoais quanto ao sexo, idade, estado civil, formação, atuação profissional e relação com as novas tecnologias.

Os dados foram analisados utilizando a abordagem da teoria fundamentada. Esse processo de pesquisa consiste na concomitância entre a coleta direcionada de dados e sua análise, visando à construção de uma teoria substantiva sobre fenômenos ou eventos sociais. Esse tipo de pesquisa se traduz por uma metodologia indutiva de entendimento e transformação das informações em teorias, utilizando, para tal, procedimentos bem definidos. (STRAUSS; CORBIN, 1998; CRESWELL, 2002; PANDIT, 1996).

Os dados foram segmentados e codificados (codificação axial), identificando-se similaridades e diferenças, originando as categorias para o estudo. A partir da análise das entrevistas, foi elaborado um questionário, que pode ser utilizado para compreender as relações entre diferentes variáveis e a diferença 176 entre grupos, uma vez que ele não se presta à análise de casos individuais. (MOREIRA, 2004).

questionário continha questões objetivas e uma escala de Likert. As questões objetivas, específicas para professores de ciências, coletaram informações sobre o perfil do participante, sobre a motivação inicial e ao longo do curso. Ele foi inicialmente aplicado como pré-teste em 11 professores, entre eles quatro doutorandos da Feusp, que, na oportunidade, realizavam o curso e fizeram sugestões e críticas. Cento e trinta e oito (138) questionários foram enviados e 75 foram recebidos, o que representa um retorno de aproximadamente $55 \%$.

A amostra do estudo é composta por 75 professores de ciências, 13 homens e 62 mulheres, que realizaram o curso em uma das duas oportunidades. Quarenta e cinco (51,7\%) realizaram a primeira edição do curso no primeiro semestre de 2007. Os outros 30 professores realizaram a formação no segundo semestre do mesmo ano, num projeto de parceria entre a Feusp e a Universidade Federal de Sergipe.

Em relação ao perfil dos PC, foram coletados dados sobre sexo; idade; estado civil; formação, que mostra a formação acadêmica inicial e a 
proveniente da pós-graduação; atuação profissional, que retrata o número de escolas onde os professores atuavam, o nível de ensino, o tipo de instituição e a jornada de trabalho; tempo de magistério, que mostra o tempo que o professor estava na profissão; relação com as novas tecnologias, que traz informações sobre a relação desses profissionais com o computador, com a internet e com a EaD (fluência tecnológica).

Quanto à motivação ao longo do curso, foram identificados a partir das entrevistas os "fatores motivadores durante a formação". Esses fatores, 14 afirmações, foram elencadas para que os professores identificassem aquelas mais relevantes e que contribuíram, mantendo-os interessados e motivados ao longo da FCD.

Em relação à motivação inicial, utilizou-se uma escala de Likert, bastante usada nos estudos sociais. Ela é do tipo nominal e mensura atitudes e opiniões dos sujeitos. Uebersax (2006) afirma que a escala consta de itens que tratam o objeto de estudo, positiva e negativamente. Nela, as atitudes são analisadas como variáveis latentes que surgem da soma das respostas de um conjunto de afirmações.

A escala continha 27 itens com variação de zero a quatro. Após análise no pré-teste e de hipóteses prévias, foram criados três grupos de variáveis latentes denominadas de domínio dos motivos pessoais (DMP), profissionais (DMPR) e de conveniência (DMC).

Com as médias obtidas, em relação à motivação inicial, foram testadas as variáveis latentes mediante o processo de soma dos itens que apresentaram consistência interna significativa. Para tal, foi realizado o teste Alpha de Cronbach que, segundo Pestana e Gageiro (2005, p. 524), mensura a "[...] proporção da variabilidade nas respostas que resulta de diferenças nos inquiridos [...]", sendo aceitável um Alpha > 0,6 em estudos sociais.

O Alpha das variáveis latentes da motivação inicial, domínio dos motivos pessoais, profissionais e de conveniência, foi, respectivamente, de 0,709; 0,63 e 0,61.

As variáveis Sexo, Idade, Formação, Experiência na EaD e Tempo de docência, do perfil, foram analisadas relacionadas com os domínios da escala da motivação inicial. Os dados advindos das escalas foram analisados em uma perspectiva quantitativa utilizando o Statistical Package for the Social Sciences (SPSS 16.0 for Windows). 
Para a comparação dos domínios segundo gênero, possuir ou não pós-graduação e ter ou não experiência na EaD foram utilizados testes não-paramétricos pelas características dos dados (teste de Mann-Whitney para amostras independentes). Para a comparação entre o Tempo de docência e os domínios foi utilizado o teste de Kruskal-Wallis, também não-paramétrico, para mais de uma amostra independente seguido do teste de Post-Hoc quando era significativo. Para a análise entre a variável idade e os domínios, foi utilizada a correlação de Spearman (teste não paramétrico). Para todas as comparações, adotou-se um nível de significância $a=0,05$.

Resultados e discussão

$\bigcirc$ perfil dos professores

Quadro 2

Perfil dos participantes dos cursos

\begin{tabular}{|c|c|c|c|}
\hline Perfil & $\%$ & Perfil & $\%$ \\
\hline \multirow[b]{2}{*}{ Gênero } & \multirow[t]{2}{*}{ Mulheres } & Atuação em uma escola & $56,7 \%$ \\
\hline & & $\begin{array}{l}\text { Atuação em escolas } \\
\text { públicas estaduais }\end{array}$ & $53,3 \%$ \\
\hline Estado civil & $\begin{array}{l}\text { Casadas } \\
54,85 \%\end{array}$ & $\begin{array}{l}\text { Atuação no ensino } \\
\text { fundamental II }\end{array}$ & $78,3 \%$ \\
\hline Média de idade & $\begin{array}{c}33 \text { anos } \\
\text { (Aproximadamente) }\end{array}$ & $\begin{array}{c}\text { Jornada de trabalho de até } \\
40 \text { horas semanais }\end{array}$ & $66,6 \%$ \\
\hline $\begin{array}{l}\text { Formado em biologia } \\
\text { com licenciatura plena }\end{array}$ & $60 \%$ & $\begin{array}{l}\text { Mais do que cinco anos } \\
\text { de formação }\end{array}$ & $55,9 \%$ \\
\hline $\begin{array}{l}\text { Algum tipo de pós- } \\
\text { graduação }\end{array}$ & $52 \%$ & $\begin{array}{l}\text { Tinha um nível } \\
\text { intermediário em relação } \\
\text { ao uso das novas } \\
\text { tecnologias }\end{array}$ & $87,6 \%$ \\
\hline & & $\begin{array}{l}\text { Não apresentava nenhuma } \\
\text { experiência em EaD }\end{array}$ & $52 \%$ \\
\hline
\end{tabular}


Os participantes de cursos de EaD têm certas características que formam o perfil típico do aluno que estuda a distância. No entanto, essas características não são homogêneas, mas são, geralmente, uma combinação de variáveis demográficas, situacionais e sociais. Os primeiros estudos em relação ao perfil investigaram as características demográficas e a situação familiar e social. Nos últimos anos, as características afetivas passaram também a ser exploradas, mas a grande maioria dos estudos continua buscando um perfil do aluno, especialmente em termos de personalidade, estilos de aprendizagem e motivação. (RURATO; GOLVEIA; GOLVEIA, 2007).

Dos dados perfil dos participantes (Quadro 2), algumas categorias foram examinadas mais detalhadamente, pois elas fornecem elementos importantes para aqueles que atuam na FCD para professores de ciências: a) a questão do gênero, o grande número de mulheres envolvidas na formação; b) a idade, a participação de professores jovens e idosos; c) o grande número de professores de escolas públicas estaduais e com altas jornadas de trabalho, o que contesta a imagem de que esses docentes são resistentes a qualquer tipo de formação; d) o tempo de docência, a participação no curso de PC com mais de 30 anos.

a) $\bigcirc$ grande número de mulheres que participaram do curso pode ser explicado pelo fato de que o quadro de professores do magistério do Ensino Fundamental II é formado por uma maioria de docentes do sexo feminino, aproximadamente 75\%. (MEC/INEP, 2007). Outra possível explicação relaciona-se à questão de que a EaD oferece maior flexibilidade de horários, pois as mulheres, no dia a dia, têm dupla jornada acrescida pela presença de filhos. A intensa participação das mulheres no mercado de trabalho associada ao acúmulo de trabalho e das tarefas de casa têm feito com que elas considerem a EaD como uma opção de FCD. (FERREIRA; MENDONÇA, 2007).

b) Em relação à idade dos professores, participaram da formação professores jovens (20 anos) e outros mais idosos (56 anos), com a média de idade se aproximando de 33 anos. Essa variação de idade sugere que esses são professores que estavam em plena atividade produtiva, e que a FCD, voltada para suas necessidades, se constituiu numa fonte de auxílio na busca de novos conhecimentos.

c) Participou da formação um grande número de professores de escolas públicas estaduais e com altas jornadas de trabalho. Esse fato contraria a 
imagem amplamente difundida de que professores desse tipo de escola são resistentes a qualquer tipo de formação e não buscam novas alternativas para o aprimoramento profissional. Esses resultados indicam que o tipo de formação contínua que está sendo efetivamente oferecida para esses profissionais, caso de fato encontre neles resistência, pode não ter formato adequado. Assim, em vez de concluir que os docentes são supostamente refratários a qualquer tipo de formação, seria lícito concluir que certo tipo de oferta de continuidade de estudos não é adequada, uma vez que foi colhida vasta gama de evidências possibilitando ampliar os conhecimentos desses professores, utilizando a modalidade de curso a distância.

d) Em relação ao tempo de docência, quase 50\% dos profissionais tinham menos do que cinco anos de formação e iniciavam a carreira no magistério e outros com mais de 20 de experiência (quase 25\%) e alguns ainda com mais de 30 anos de profissão (aproximadamente 3\%). Uma explicação possível para o fato de muitos PC com mais de 20 anos de experiência terem realizado a FCD está relacionada à questão de que muitas pessoas, nos dias atuais, estão prolongando suas vidas produtivas, estudando e trabalhando mesmo depois de aposentadas. A aposentadoria não tem se constituído num 180 período de descanso ou de dependência. No Brasil, 71\% das pessoas gostariam de continuar trabalhando o máximo possível. Elas querem trabalhar e estudar além da idade limite para a aposentadoria. (OXFORD INSTITUTE OF AGEING \& HSBC, 2007).

Essas informações podem servir de recursos para aqueles que criam e atuam na FCD. Elas podem auxiliar os formadores a oferecer conhecimentos mais ajustados aos PC para facilitar as aprendizagens, ov o enfrentamento das dificuldades, possibilitando manter ou ampliar as motivações dos professores.

Conhecer o perfil (sexo, estado civil, a idade, o tipo de formação, a atuação e em que tipo de instituição, a jornada de trabalho, as experiências com as novas tecnologias e com a EaDl pode ainda contribuir para a diminuição da desistência do PC no curso, sobretudo, no caso das mulheres, casadas com encargos familiares, que significa tarefas extras que podem afastá-las da formação. No entanto, os estudos sobre o perfil devem estar atrelados à motivação inicial. 


\section{A motivação inicial dos professores de ciências}

É bastante variada a motivação inicial dos professores de ciências que participaram de cursos de formação contínua a distância na universidade pública. Dentre os doze itens mais pontuados entre os três domínios (Tabela 1), houve predomínio dos motivos profissionais no somatório das médias (Domínio dos Motivos Pessoais, média 3, 10; Conveniência 3,25 e Profissional 3,43). A Tabela 1 mostra os itens e as médias.

\section{Tabela 1}

Motivação inicial: itens mais pontuados/média/desvio padrão

\begin{tabular}{|c|c|c|c|c|}
\hline Item & Afirmação & Média & Domínio & $\begin{array}{l}\text { Desvio- } \\
\text { Padrão }\end{array}$ \\
\hline MIO3 & $\begin{array}{l}\text { Interesse pelo tema Educação } \\
\text { Nutricional para minhas aulas }\end{array}$ & 3,84 & Profiss. & ,436 \\
\hline MI10 & $\begin{array}{l}\text { Aprimorar meus conhecimentos } \\
\text { profissionais sobre o tema }\end{array}$ & 3,71 & Profiss. & ,653 \\
\hline MI11 & $\begin{array}{c}\text { Aplicar, profissionalmente, os } \\
\text { conhecimentos do curso junto aos } \\
\text { alunos }\end{array}$ & 3,50 & Profiss. & 1,113 \\
\hline MI21 & $\begin{array}{c}\text { Flexibilidade de horários por ser } \\
\text { a distância }\end{array}$ & 3,35 & Conven. & 1,020 \\
\hline MI15 & $\begin{array}{l}\text { O fato do curso melhorar a } \\
\text { qualidade de minhas aulas }\end{array}$ & 3,31 & Profiss. & 1,185 \\
\hline MI25 & Poder conciliar trabalho e estudo & 3,28 & Conven. & 1,008 \\
\hline MI24 & $\begin{array}{l}\text { Oportunidade no momento em } \\
\text { que o curso foi aberto }\end{array}$ & 3,27 & Pessoal & 1,031 \\
\hline MI23 & Ter as tecnologias disponíveis & 3,24 & Conven. & 867 \\
\hline MIO6 & $\begin{array}{c}\text { Interesse, pois o curso de } \\
\text { Educação Nutricional era gratuito }\end{array}$ & 3,22 & Pessoal & 1,264 \\
\hline MI26 & Poder conciliar estudo e família & 3,11 & Conven. & 1,169 \\
\hline
\end{tabular}




\section{MI08 \\ Interesse por informações para melhorar minha alimentação \\ 3,05 Pessoal \\ 1,038 \\ Interesse em vivenciar a \\ MIO1 experiência da Educação a Distância em um curso de 3,03 Pessoal Educação Nutricional}

A relevância do tema (MIO3) foi um dos fatores que influenciou muitos professores de ciências na escolha por esse tipo de formação. A busca por novos conhecimentos contextualizados (MI 10) que possuem ligações com a vida profissional e pessoal do PC também foi um importante fator que os motivou para a formação contínua a distância.

A questão da flexibilidade de horários (MI2 1) também se constituiu em algo bastante relevante na opinião dos PC. No caso específico desse grupo de profissionais, sendo a maioria casados e com elevadas cargas de trabalho semanal, essa flexibilidade representou a possibilidade de poder se atualizar nos momentos vagos. Isso pode explicar alguns dos motivos que levam os pro-

182 fessores a não receber bem alguma proposta de curso que não tenha a mesma flexibilidade de horários, sem qualquer alívio das jornadas de trabalho. Essas seriam indicações importantes para dirigentes educacionais no planejamento de uma política de FCD para professores.

Algumas pesquisas já exploraram a motivação inicial, os motivos, que levam os adultos à formação a distância. Moore e Kearsley (2007) afirmam que os alunos que se matriculam em cursos da EaD apresentam vários motivos como procurar compensar a Educação do nível médio, realizar créditos universitários, aprender, passar o tempo, investimento pessoal, melhorar a renda e a empregabilidade. No entanto, a razão mais comum consiste em desenvolver ou aperfeiçoar conhecimentos necessários para o emprego, portanto relaciona-se com as questões profissionais.

O'Lawrence (2007) sinaliza que o que mais motiva os adultos a participarem é a flexibilidade da EaD, permitindo a conciliação da família, trabalho e estudo e a possibilidade de estudar em casa. Fiuza (2002), analisando aspectos motivacionais de alunos em relação à EaD, mostrou três grupos de fatores motivadores que levam os profissionais para a EaD: pessoais, profissionais e 
práticos. Ela procedeu a uma análise das frequências das respostas, constatando que os aspectos pessoais eram ligeiramente preponderantes.

Em um estudo qualitativo preliminar com 55 professores de ciências de nove estados brasileiros, Garcia, Bizzo e Lemos (2008) elencaram os motivos que atraem esses professores para cursos de FCD, mostrando que os fatores profissionais exerceram maior influência no momento da escolha do curso.

No entanto, esses estudos descritos não separaram os motivos entre os subgrupos (perfil) dentro de uma mesma população. Esta pesquisa aqui apresentada, além de elencar os motivos que atraem os PC para a FCD, amplia a compreensão sobre os motivos iniciais, explorando o impacto do perfil dos PC que foram atraídos para o curso (gênero, idade, formação, experiência no ensino e em EaD) sobre a motivação inicial para a formação contínua a distância.

As análises realizadas entre os domínios e as variáveis Sexo, Idade, Formação, Experiência na EaD e Tempo de docência, com o intuito de construir um panorama mais amplo e mais detalhado sobre a percepção dos PC, mostraram que houve certo equilíbrio nos fatores dos três domínios para influenciar os PC na escolha do curso. No entanto, existiu certo destaque para o domínio dos motivos profissionais, influenciando, em alguns casos, mais do que os outros dois domínios. Essa análise quantitativa foi relevante, pois confirmou a apreciação dos dados qualitativos.

As análises revelaram em relação ao gênero que tanto para os homens como para as mulheres os fatores motivadores de cada um dos três domínios exerceram influência no momento da escolha pela formação a distância (não houve diferença estatisticamente significativa). No entanto, a prudência intelectual recomenda, nesse caso, não tirar conclusões sem ter amostras significativas e plenamente equiparáveis.

Em relação à correlação entre variável Idade e os domínios (Tabela 2), foi possível constatar que PC com mais idade foram mais influenciados pelos fatores profissionais. $\bigcirc$ mesmo aconteceu com o tempo de docência (Tabela 3). Professores com mais de dez anos de docência foram mais influenciados pelos fatores do domínio profissional. 
Tabela 2

Relação entre idade e os domínios

\begin{tabular}{ccc}
\hline Idade & I & p-valor* \\
DMP & $-0,117$ & 0,326 \\
DMPR & 0,278 & 0,017 \\
DMC & 0,168 & 0,154 \\
\hline \multicolumn{2}{c}{ *Correlação de Spearman }
\end{tabular}

Tabela 3

Relação entre o tempo de docência e os domínios.

\begin{tabular}{cccccc}
\hline Tempo de & $<5$ & $5-10$ & $>10$ & & \\
docência & Média (SD) & Média (SD) & Média (SD) & p-valor* & Post Hoc \\
DMP & $27,10(6,89)$ & $24,84(5,63)$ & $24,89(6,38)$ & 0,200 & \\
& & & & & $<5=5-10$
\end{tabular}

184

DMPR $27,17(5,01) \quad 27,00(5,38) \quad 30,63(4,87) \quad 0,013 \quad \begin{gathered}5-10 \neq \\ >10\end{gathered}$

$<5 \neq>10$

DMC $\quad 23,89(5,89) \quad 26,16(5,36) \quad 26,52(4,9) \quad 0,297$

*Teste Kruskal-Wallis para mais de uma amostra independente

A análise, da formação em nível de pós-graduação dos PC e dos domínios (Tabela 4), indicou que, para os PC que tinham algum tipo de pós-graduação, os fatores do domínio profissional influenciaram mais na hora da escolha do curso. Os motivos profissionais se apresentam como mais determinantes para aqueles que possuíam pós-graduação. Embora sinalizado de forma superficial e carecendo de estudos mais aprofundados, esse dado é interessante, pois contraria a crítica de que a escolha por EaD recai sobre aqueles que não querem estudar. 
Tabela 4

Relação entre a variável pós-graduação e os domínios

\begin{tabular}{cccc}
\hline Pós-graduação & Não & Sim & p-valor* \\
& Média (SD) & Média (SD) & \\
DMP & $26,91(5,42)$ & $24,71(6,97)$ & 0,175 \\
DMPR & $26,48(5,35)$ & $29,46(4,80)$ & 0,014 \\
DMC & $25,02(5,87)$ & $25,66(5,19)$ & 0,603 \\
\hline
\end{tabular}

*Teste Mann-Whitney para amostras independentes

Em relação à experiência em EaD e os domínios, não há diferença estatisticamente significativa entre as médias dos domínios dos motivos pessoais, profissionais e de conveniência. Experiência não exerceu influência no momento da escolha pela formação a distância.

Sintetizando, não foi encontrada uma variável que explicasse, isoladamente, a motivação inicial dos PC. Os três domínios foram importantes para atrair os professores para o curso. No entanto, as análises mostraram que o domínio dos motivos profissionais exerceu maior influência, sendo mais decisivo no momento da escolha do curso. Para professores com maior idade, com pós-graduação e com mais dez anos de docência esses fatores profissionais foram mais decisivos em relação à decisão de realizar a FCD.

Uma conclusão que se pode depreender desses dados em relação aos motivos que atraíram esses profissionais para a FCD é que o foco desses professores, mais "maduros", experientes na profissão e com maior formação, estava sobre as questões profissionais. Esses resultados sinalizam a necessidade da articulação de ações e estratégias bem equilibradas, para atrair os PC para a formação contínua a distância em relação aos três domínios, sobretudo para os domínios pessoais e de conveniência.

\section{A motivação dos professores ao longo da formação}

A partir das entrevistas iniciais, foram selecionadas 14 afirmativas que representaram os fatores que, na opinião dos PC, foram importantes para mantê-los motivados durante a FCD. 


\section{Tabela 5}

Distribuição das afirmativas de motivação dos PC durante o curso - 2007

\section{Item}

01 Meu interesse pelo tema: por ele ser muito interessante e atual

02

11

12

14

08

03

10

186

A flexibilidade de horários

A boa qualidade das aulas

A relevância e utilidade do curso para as minhas aulas

\section{Frequência absoluta}

74

71

66

56

54

52

47

47

45

43

42

27

22

17
Frequência relativa (\%)

98,7

94,7

88,0

74,7

72,0

69,3

62,7

62,7

60,0

57,3

56,0

36,0

29,3

04 A interação com os colegas, com os problemas e discussões

As atividades realizadas durante o curso (pergunta relâmpago)

"Meu interesse pelo tema: por ele ser muito interessante e atual" $(01)$, "A flexibilidade de horários" (02), "A boa qualidade das aulas" (1 1); "A relevância e utilidade do curso para as minhas aulas" (12) e "A relevância dos conteúdos para a minha alimentação" (14), foram os itens mais pontuados, respectivamente com 98,7\%; 94,7\%; 88\%, 74,7\% e 72\%.

Esses fatores encontrados foram aqueles que se apresentaram como determinantes para que os PC mantivessem o interesse ao longo da formação. 
A qualidade das aulas refere-se aos conteúdos atuais, à contextualização realizada através das explicações do professor e às atividades realizadas durante o curso. A relevância dos conteúdos para a vida pessoal e profissional relaciona-se às informações práticas que os PC obtiveram e puderam colocar em ação com seus alunos e com suas famílias.

A qualidade das aulas e a relevância dos conteúdos para a vida pessoal e profissional são dois fatores que devem ser articulados com muita atenção para motivar os PC durante o período de formação.

Destacam-se também a questão da interação e dos laços afetivos que foram citados por quase $40 \%$ dos PC como fatores relevantes para mantê-los motivados ao longo do curso. A criação de laços afetivos foi determinante para a motivação e, consequentemente, para a aprendizagem do professor. $\bigcirc$ depoimento de uma professora (PC 17) ilustra tal situação:

Querido professor... não é todo dia que temos a oportunidade de "rejuvenescer" culturalmente, quanto mais de conhecer pessoas que deixam sua marca em nossa vida!... queria agradecer e lembrar os momentos que construímos e vivemos juntos e que nasceram na simplicidade de um curso on-line e que acabou por conquistar carinhosamente os participantes. (PROFESSORA CURSISTA 17, 2007).

Os laços afetivos fortalecem a motivação, o interesse do PC, e isso contribui com o debate sobre a delicada questão da desistência e do abandono dos cursos a distância. De fato, a motivação tem sido uma das categorias estudadas por pesquisadores que tentam compreender mais sobre a questão da evasão na EaD. Ela é uma variável que interfere tanto na questão da aprendizagem como na questão da desistência dos cursos. No entanto, outros fatores tais como o perfil dos alunos, suas características individuais e as circunstâncias de vida também estão envolvidas.

Na opinião de Xenos, Pierrakeas e Pintelas (2002), entre os fatores que causam a desistência do aluno de cursos a distância está a motivação. Esta é uma das variáveis que os formadores devem lidar com cautela e atenção durante todo o período de formação.

Vários autores sugerem atividades estimulantes e motivadoras para que sejam usadas desde o começo do curso ISANTOS, TOMOTAKE, OLIVEIRA NETO, CAZARINI, ARAÚJO E OLIVEIRA, 2008); entre elas, Favero e Franco (2006) recomendam o diálogo para auxiliar na manutenção da motivação 
dos alunos e diminuir a evasão. Visser (2001) sugere que a motivação seja trabalhada utilizando materiais de aprendizagem, e-mail e chats, e Tractenberg (2007) recomenda, para manter o interesse dos estudantes, cooperação entre professor e aluno como fator motivacional e como forma de enfrentar o desafio de ensinar e aprender. Por fim, Flores (2009) sinaliza que, em ambientes virtuais, o feedback é uma ferramenta fundamental no trato com a motivação.

No entanto, este presente estudo sugere, para potencializar a aprendizagem do PC e para auxiliar na questão da evasão dos cursos, uma combinação de fatores interconectados. Atenção especial deve ser atribuída ao tema da FCD para os professores de ciências, focando a atualidade e sua pertinência para a vida pessoal e profissional do professor; a boa qualidade das aulas, enfatizando conteúdos relevantes e atuais, atividades de resolução de problemas, destacando a contextualização e o papel do professor; e a criação de laços afetivos, realçando o envolvimento, a criação de vínculos e, sobretudo, a sintonia de interesses e de dificuldades.

\section{Considerações e implicações finais}

Os resultados aqui apresentados são relevantes para que as universidades possam ampliar seus papéis em relação à Educação (formação contínua) e à sociedade, contribuindo com a construção de novos cursos de FCD, melhorando a formação do professor e, consequentemente, o Ensino de Ciências.

Os resultados sugerem a necessidade de compreender os diversos aspectos da formação contínua a distância para projetar novos cursos (relevância do tema, flexibilidade, contextualização dos conteúdos), pois esses são elementos relevantes que motivaram os professores de ciências para participar do curso. A partir da compreensão da motivação inicial (relacionada ao perfil) para a formação contínua a distância, formadores de professores têm à disposição alguns elementos concretos para atrair professores de ciências para essa formação preparando-os, entre outras coisas, para as inovações e reformas.

Este estudo fornece também elementos concretos para uma reflexão sobre a construção de atividades diferenciadas para manter os PC motivados durante o curso, atendendo a seus interesses, potencializando suas aprendizagens, auxiliando na complexa tarefa de redução da evasão. Para tal, recomenda-se uma combinação de fatores interconectados, tais como: tema da 
formação pertinente para a vida pessoal e profissional do professor, conteúdos relevantes, contextualizados e atuais, atividades de resolução de problemas e a criação de laços afetivos, sobretudo através da sintonia de interesses e de dificuldades vividos pelos professores de ciências.

Esses elementos do perfil e das motivações encontrados neste estudo possibilitam reflexões sobre adaptações no ambiente virtual de aprendizagem e nas ferramentas de interação (fórum, chats, e-mail, wikis) e também sobre as metodologias de ensino mais apropriadas para serem utilizadas. Formadores de professores de ciências podem preparar estratégias de aprendizagem mais personalizadas para auxiliar na motivação do professor de ciências. Reuniões presenciais ao longo do curso, estratégias de estudo e de orientação, chats privados, videoconferências, mensagens por email são algumas atividades que podem ser criadas.

Este estudo contribui também para revelar que as pesquisas devem ser ampliadas para além da investigação das características pessoais e da motivação inicial dos alunos da EaD. Elas devem ser mais integradas, abarcando o perfil, a motivação inicial e aquela durante a formação. Ao mesmo tempo, a motivação inicial, ou seja, os motivos que atraem os professores para FCD, deve ser relacionada ao perfil desse professor (gênero, idade, formação, fluência tecnologia), visto que tal situação fornece mais elementos para os formadores.

\section{Referências}

ABED. Associação Brasileira de Educação a Distância. Censo EaD Brasil, 2010. Pearson Education do Brasil, São Paulo, ABED, 2010.

ADAMS, Paul E.; TILLOTSON, John. W. Why research in the service of science teacher education in needed. Journal of Research in Science teaching, Malden, USA, v. 32, n. 5, p. $441-443,1995$.

BERGAMINI, Cecilia Whitaker. Psicologia aplicada a administradores. 3. ed. São Paulo: Atlas, 1992.

BRASIL. Lei de Diretrizes e Bases da Educação Nacional n. 9.394, de 20 e dezembro de 1996. Disponivel em: <http://www.google.com.br/urlesa=t\&rct=i\&q=\&esrc=s\&source=w eb\&cd= 1 \&cad=rja\&ved=0CCAQFjAA\&url=http\%3A\%2F\%2Fwww. ufrpe. br\%2Fdownload. php\%3FendArquivo\%3Dnoticias\%2F4248_LDB.pdf\&ei=Sl9kUMHeDZTc8ATghYHIAw\&usg= 
AFQjCNFKeXsIQLRECP8Rej9izLylp_DmqQ\&sig2=q8ISXnTzx+R4F2IpyqAMvA>. Acesso em: 21 abr. 2005.

Decreto n. 5.622, de 19 de dezembro de 2005. Regulamenta o artigo 80 da Lei 9.394/96. Diário Oficial [da] República Federativa do Brasil, Poder Executivo, Brasília, DF, 20 dez. 2005. Seção 1, n²43, p. 1-4.

CAMPOS, Dinah Martins de Souza. Psicologia da aprendizagem. 23. ed. Petrópolis: Vozes, 1993.

COELHO, Maria de Lourdes. A evasão nos cursos de formação continuada de professores universitários na modalidade de educação a distância via internet. 2010 . Disponível em: <http://www2.abed.org.br/visualizaDocumento.asp?Documento_ID=10>. Acesso em: 30 jun. 2010.

CRESWELL, Joseph. W. Educational research: planning, conducting, and evaluating quantitative and qualitative research. New Jersey: Pearson Education, 2002.

CUNHA, Ana Maria de Oliveira; KRASILCHILK, Myriam. A formação continuada de professores de ciências: percepções a partir de uma experiência, trabalho. In. REUNIÃO ANUAL DA ASSOCIAÇÃO NACIONAL DE PÓS-GRADUAÇÃO E PESQUISA EM EDUCAÇÃO, 29., 2000, Caxambu. Anais... Caxambu: ANPEd, 2000. p. 1-14.

CUNHA, Silvio Luiz Souza. Reflexões sobre o EaD no ensino de física. Revista Brasileira de Ensino de Física, São Paulo, v. 28, n. 2, p. 151-153, 2006.

FAVERO, Rute Vera Maria. Dialogar ou evadir: eis a questão: um estudo sobre a permanência e a evasão na EaD no Estado do Rio Grande do Sul. 2006. 167f. Dissertação Mestrado em Educação) - Programa de Pós-Graduação em Educação, Universidade Federal do Rio Grande do Sul. Porto Alegre. 2006.

FAVERO Rute Vera Maria; FRANCO Sergio Roberto Kieling. Um estudo sobre a permanência e a evasão na Educação a Distância. Novas Tecnologias na Educação, Rio Grande do Sul, v. 4, n. 2, p. 1-10, dez., 2006.

FERREIRA, Maria Luiza Ribeiro. A Motivação nos adultos: factor fundamental de aproveitamento no ensino a distância. SINAL - Revista do Instituto Português de Ensino a Distância, Lisboa, n. 1, p. 29-43, 1985.

FERREIRA, Zuleika Nunes; MENDONÇA, Gilda Aquino de Araujo. $\bigcirc$ perfil do aluno de cursos a distância no ambiente TELEDUC. In: CONGRESSO INTERNACIONAL DE EDUCAÇÃO A DISTÂNCIA, 13., 2007, Curitiba. Anais... CIETEP, 2007. p. 1-10. 
FEUSP. FACULDADE DE EDUCAÇÃO DA UNIVERSIDADE DE SAÕ PAULO. Programa oficial do curso "Educação Nutricional" a distância. São Paulo: USP, 2007.

FLICK, Uwe. Uma introdução à pesquisa qualitativa. 3. ed. Porto Alegre: BOOKMAN, 2009.

FIUZA Patricia Jantsch. Aspectos motivacionais na educação a distância análise estratégica e dimensionamento de ações. 2002. 124f. Dissertação (Mestrado em Engenharia de Produção) - Programa de Pós- Graduação em Engenharia de Produção, Universidade Federal de Santa Catarina. Florianópolis, 2002.

FLORES, Angelita Marçal. O feedback como recurso para a motivação e avaliação da aprendizagem na educação a distância. Disponível em: <http://www.abed.org.br/congresso2009/CD/trabalhos/1552009182855.pdf>. Acesso em: 18 ago. 2011.

GARCIA, Paulo Sergio; BIZZO, Nelio; LEMOS, Carolina. Study on the science teachers'ccontinuing education at distance In: IOSTE SYMPOSIUM, THE USE OF SCIENCE AND TECHNOLOGY EDUCATION FOR PEACE AND SUSTAINABLE DEVELOPMENT, 13., 2008, Kuadası /Turkey. Ankara: Palme Publications \& Bookshops Co, 2008. p. 243-249.

GIBSON, Chere Campbell. Learners and learning: the need for theory. In: MOORE, Michael. Grahame; ANDERSON, Willian. Georger (Eds.) Handbook of distance education. Mahwah/NJ: Lawrence Erlbaum Associates, 2003.

GOMEZ, Rita Cássia. Guarezi. Educação a Distância: Uma alternativa para a Formação de Professores e demais Profissionais na Sociedade do Conhecimento. 2000. 169p. Dissertação (Mestrado em engenharia da produção). Florianópolis. Universidade Federal Santa Catarina, 2000.

HERSEY, Paul; BLANCHARD, H. Kenneth. Psicologia para administradores: as teorias e as técnicas da liderança situacional. Tradução Edwino Aloysius. Royer. São Paulo: EPU, 1986.

MEC/INEP. Ministério da Educação. Instituto Nacional de Estudos e Pesquisas Educacionais Anísio Teixeira. Sinopses estatísticas da educação superior: graduação 2007. Disponível em: http://www.inep.gov.br/superior/censosuperior/sinopse/default.asp. Acesso em: 10 maio 2010.

KEEGAN, Desmond. Foundations of distance education. 3. ed. London: Routledge, 1996. LIMA, Luzia Mara Silva. Motivação em sala de aula: a mola propulsora da aprendizagem. In: OLIVEIRA, Gislene. de Campos. e FINI, Lucila. Diehl. Tolaine. Leituras de psicologia para 
formação de professores. Petrópolis: Vozes; Bragança Paulista: Universidade São Francisco, 2000.

MOORE Michael; KEARSLEY, Greg. Educação a distância: uma visão integrada. Thomson Learning, São Paulo, 2007.

MOREIRA, José Manuel. Questionários: teoria e prática. Coimbra: Almedina, 2004.

MURRAY, Eduard. Motivação e emoção. 5. ed. Tradução Álvaro Cabral. Rio de Janeiro: Guanabara, 1986.

O'LAWRENCE Henry. An Overview of the Influences of Distance Learning on Adult Learners. Journal of educational and human development, Saint Cloud, v. 1, n. 1, p. 1-8, 2007.

OXFORD INSTITUTE OF AGEING \& HSBC. Brasileiro quer trabalhar, mesmo aposentado. 2007. Disponível em: <www.administradores.com.br/noticias/brasileiro_quer_trabalhar_ mesmo_aposentado/10775>. Acesso em: 17 maio 2009.

PALLOFF Rena M.; PRATT, Keith. The virtual student: a profile and guide to working with on-line students. San Francisco: Jossey-Bass Pfeiffer, 2003.

PANDIT, Naresh. R. The creation of theory: a recent application of the grounded theory 192 method, the qualitative report, 2, 4, 1996. In: PATTON, Michael. Quinn. Qualitative evaluation and research methods (2nd Ed.). Newbury Park, CA: Sage, 1996.

PESTANA, Maria. Helena; GAGEIRO, João. Nunes. Análise de dados para ciências sociais - a complementaridade do SPSS. Lisboa: Edições Sílabo, 2005.

PROFESSORA CUSISTA 17. Entrevista oral, São Paulo, 29 nov. 2007.

RURATO, Paulo; GOLVEIA Luís Borges; GOLVEIA Joaquin Borges As características dos aprendentes na educação a distância: a particularidade de uma análise individualizada. Revista da Faculdade de Ciências Sociais e Humanas, Porto (Portugal), n. 4, p 100-1 17, 2007.

As características dos aprendentes na educação a distância: factores de motivação.

Revista da Faculdade de Ciências e Tecnologia, Porto (Portugal), n. 4, p 80-92, 2007a.

SANTOS, Elaine Maria dos; TOMOTAKE, Maria Eliza; OlIVEIRA NETO, José Dultra de; CAZARINI, Edson Walmir; ARAÚJO, Elenise Maria de; OlIVEIRA, Selma Regina Martins. Evasão na educação a distância: identificando causas e propondo estratégias de prevenção. In: CONGRESSO INTERNACIONAL DE EaD. Associação Brasileira de Educação a Distância, 2008, Santos. 2008. Disponível em: <http://www.abed.org.br/congresso2008/tc/511200845607PM.pdf>. Acesso em: 23 nov. 2008. 
STRAUSS, Anselm; CORBIN, Juliet. Basics of qualitative research: techniques and procedures for developing grounded theory. 2. ed. London: Sage Publications, 1998.

UEBERSAX, John S. Likert scales: dispelling the confusion. Statistical methods for rater agreement website. 2006. Disponível em: <http://ourworld.compuserve.com/homepages/ isuebersax/likert2.htm>. Acesso em: 20 fev. 2009.

UNIVERSIDADE DE SÃO PAULO. RESOLUÇÃO CoCEx n. 5007, 25 de março de 2003. (D.O.E. - 27.03.2003 - Retificada em 29.03.2003). Regulamenta a Educação a Distância nos Cursos de Extensão da Universidade de São Paulo.

TRACTENBERG, Leonel. Motivação para o estudo da docência colaborativa online: um novo território a explorar. Disponível em: <http://www.abed.org.br/congresso2007/ tc/562007122423AM.pdf>. Acesso em: 14 out. 2011.

VISSER, Lya. Applying motivational communication in distance learning support. In: PROCEEDINGS OF THE INTERNATIONAL CONFERENCE ON DATA ENGINEERING, 17 TH., 2001 , Pennsylvania. Pennsylvania: Pennsylvania State University, v. 2, n. 6, 2001.

XENOS, Michalis; PIERRAKEAS, Christos; PINTELAS, Panagiotis. "A survey on student dropout rates and dropout causes concerning the students in the Course of Informatics of the Hellenic Open University". Computers \& Education, Greece, v. 39, n. 4, p. 361-377, 2002.

YIN, Robert. Aplications of case study research. Thousand Oaks: SAGE Publications, 1993.

Estudo de caso - planejamento e métodos. 3. ed. Porto Alegre: Bookman, 2005.

Prof. Dr. Paulo Sérgio Garcia Universidade de São Paulo Faculdade de Educação Grupos de Pesquisa | Ensino de Ciência e Ensino de Ciências e Educação a Distância 
Email | garciaps@usp.br

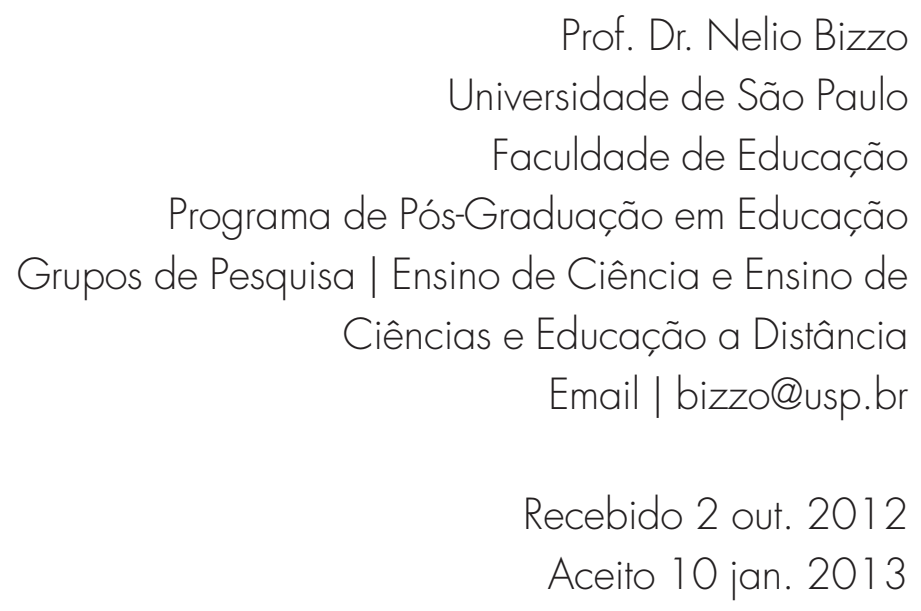

194 